\section{Could Pathophysiology Failure Be Ruled Out?}

\section{To the Editor:}

I read with great interest the article by von Arx et $\mathrm{al}^{1}$ published in the The American Journal of Medicine. Arx et al presented a case showing that renal denervation did not lower blood pressure in a drug-naïve patient and provided evidence that the nonresponsiveness of blood pressure to renal denervation may be due to arterial stiffness.

One of the possible reasons for the nonresponsiveness of blood pressure to renal denervation is pathophysiology failure. Pathophysiology failure means that renal sympathetic activity does not increase in a hypertensive patient. Arx et al $^{1}$ stated that they ruled out this possibility because systolic blood pressure variability of this patient was decreased from $18.0 \mathrm{~mm} \mathrm{Hg}$ at baseline to $12.6 \mathrm{~mm} \mathrm{Hg}$ at 3 months after renal denervation. The decrease in systolic blood pressure variability may indicate that the renal denervation procedure was successful in this patient; however, it did not provide information on whether the baseline blood pressure variability was elevated compared with that in the age-matched normotensive population. Therefore, it is still possible that renal sympathetic activity did not increase in this patient and that pathophysiology failure

Funding: This work is funded by a grant from the National Health and Medical Research Council (1062671). The funding body played no role in the production of this publication.

Conflict of Interest: None.

Authorship: The author had access to the data and played a role in writing this manuscript. may, in part, contribute to the nonresponsiveness of blood pressure to renal denervation in this patient.

Systolic blood pressure variability, as von Arx et $\mathrm{al}^{1}$ pointed out, has been reported to be correlated with muscle sympathetic nerve activity. ${ }^{2}$ However, this correlation was observed in young normotensive subjects with a mean age of 31 years. $^{2}$ This young age is different from the mean age of patients undergoing renal denervation, which is approximately 60 years. ${ }^{3,4}$ Therefore, the usefulness of systolic blood pressure variability as a proxy of sympathetic activity in the elderly population is still to be established.

Therefore, it is possible that pathophysiology failure may, in part, contribute to the nonresponsiveness of blood pressure to renal denervation in this patient.

Yutang Wang, $\mathrm{PhD}$

School of Applied and Biomedical Sciences Faculty of Science and Technology

Federation University Australia

Mount Helen, Australia

http://dx.doi.org/10.1016/j.amjmed.2014.07.044

\section{References}

1. Von Arx R, Rexhaj E, Allemann Y, et al. Lack of blood pressure lowering effect of renal denervation in a drug-naive patient with pronounced arterial stiffening. Am J Med. 2014;127(9):e3-e4.

2. Narkiewicz K, Winnicki M, Schroeder K, et al. Relationship between muscle sympathetic nerve activity and diurnal blood pressure profile. Hypertension. 2002;39:168-172.

3. Krum H, Schlaich M, Whitbourn R, et al. Catheter-based renal sympathetic denervation for resistant hypertension: a multicentre safety and proof-of-principle cohort study. Lancet. 2009;373:1275-1281.

4. Esler MD, Krum H, Sobotka PA, et al. Renal sympathetic denervation in patients with treatment-resistant hypertension (The Symplicity HTN- 2 Trial): a randomised controlled trial. Lancet. 2010;376:1903-1909. 